\title{
Indigenismos e indigenismo literario en el Boletín Titikaka (1926-1930) ${ }^{*}$
}

\author{
Begoña Pulido Herráez ${ }^{* *}$
}

Recibido el 7 de junio de 2019; aceptado el 24 de septiembre de 2019

\section{RESUMEN}

En el presente artículo se revisan los indigenismos que aparecen en la publicación Boletín Titikaka (Puno, Perú, 1926-1930), como una forma de abordar la complejidad del movimiento indigenista en la década del veinte. Se pueden distinguir indigenismos de base social, económica y cultural, pensados desde la centralidad de Lima o elaborados en núcleos de los Andes, como Puno. Se revisan en particular los relatos indigenistas que aparecieron en el Boletín durante los últimos años de publicación, proponiendo una lectura donde más que considerarlos narraciones tradicionales próximas al realismo o el costumbrismo, se observan desde el modo en que figuran las posibilidades de un diálogo cultural. Se deduce que el lirismo, el pensamiento mágico y la narración testimonial constituyen los elementos que distancian a estos relatos del realismo.

Palabras clave: Boletín Titikaka, vanguardia andina, indigenismo, indigenismo literario.

* El presente artículo fue elaborado en el marco del proyecto PAPIIT "Mito y Memoria en las literaturas andinas peruanas" (IN402319), DGAPA-UNAM.

** Universidad Nacional Autónoma de México, México. Correo electrónico: begopulido@yahoo.com. ORCID: https://orcid.org/0000-0002-9835-4194 


\title{
Indigenism and literary indigenism in the Boletín Titikaka (1926-1930)
}

\begin{abstract}
In the present article, the indigenisms that appear in the Boletín Titikaka (Puno, Perú, 1926-1930) are reviewed as a way to approach the complexity of the indigenous movement in the 1920s. Indigenisms of social, economic and cultural base can be distinguished, thought from the centrality of Lima or elaborated in cities of the Andes like Puno. The indigenist stories that appeared in the Bulletin during the last years of publication are also reviewed, proposing a reading where, rather than considering traditional narratives close to realism or costumbrismo, they are observed from the way in which the possibilities of a cultural dialogue appear. It follows that lyricism, magical thinking and the testimonial narrative form constitute the elements that distance these stories from realism.
\end{abstract}

Key words: Boletín Titikaka, andean avant-garde, indigenism, literary indigenism.

$\mathrm{E}$ ste artículo explora el movimiento indigenista de la década del veinte en Perú mediante el análisis de los diversos ensayos y textos de ficción narrativa que fueron publicados en el Boletín Titikaka (Puno, 1926-1930). El texto se inscribe en este sentido tanto en el campo de estudio de las revistas literarias y culturales como en las relecturas que el indigenismo ha tenido en los últimos años. En la década de los veinte las revistas y, en general la prensa, fueron un medio privilegiado donde se llevó a cabo la reivindicación de los pueblos indígenas tras siglos de abuso y marginación. Las primeras décadas del siglo ven la emergencia y el fortalecimiento de este movimiento cultural, social y político que se manifiesta y expresa en una variada constelación de prácticas: el ensayo, la pintura, la literatura, la fotografía. Publicaciones como el Boletín Titikaka incluyen ensayos, narraciones, poemas, grabados, una gama amplia de estas prácticas cuyo análisis permite comprender las contradicciones que anidan en el indigenismo del periodo, el papel de las publicaciones periódicas en la difusión y crítica de este movimiento reivindicador, y la participación de los intelectuales andinos en éste, el cual tenía uno de sus vértices más importantes en Lima. En efecto, en la segunda mitad de la década brota un buen número de revistas indigenistas (de vida breve y tiros cortos) tanto en provincia como en Lima, entre ellas Amauta (Lima), La Sierra (Lima), Kosko (Cuzco), Attusparia (Huaraz), Kúntur (Cuzco), Chirapu (Arequipa), Inti (Huancayo), Puna (Araviri). En las páginas de Amauta y en 
las del periódico El Mundial se desenvolvió la llamada "polémica del indigenismo” entre José Carlos Mariátegui y Luis Alberto Sánchez, en la que participó también José Ángel Escalante. En las revistas se publican avances de libros como Tempestad en los Andes (de Luis Valcárcel), o El indio nuevo (de Uriel García), entre otros ensayos y discursos que muestran particulares y diferentes visiones del indio y la cultura indígena.

El análisis de las revistas constituye un espacio privilegiado para comprender la gestación, fortalecimiento, difusión y diferentes prácticas y orientaciones del movimiento indigenista. El indigenismo se ha definido como un movimiento que busca la reivindicación política y social de las personas indígenas, en este caso, de los Andes. ${ }^{1}$ Gerardo Leibner ha señalado cómo el estudio del indigenismo de las primeras décadas del siglo veinte ha estado marcado, desde los años setenta del siglo XX, por varios momentos: de admiración hacia esos pioneros intelectuales que impulsaron los temas indígenas e incaicos en los debates nacionales y en elemento clave del discurso nacional peruano, de crítica señalando sus limitaciones en relación con los análisis marxistas posteriores, de etapa previa a la introducción franca de la antropología en los estudios andinos, de consideración de estos indigenistas como precursores de la obra de José María Arguedas, hasta enfoques recientes cada vez más críticos de este indigenismo temprano y de la labor de los indigenistas, desarrollada por criollos-mestizos urbanos a menudo desconocedores de la "realidad andina" (como sería el caso de José Carlos Mariátegui) y letrados. "Ahora [apunta Leibner] la crítica procura deconstruir el mismo discurso indigenista y también exponer sus contextos sociales constitutivos, sus diversas facetas y las funciones cumplidas, en su momento, por los mismos indigenistas". ${ }^{2}$

Mi perspectiva para este trabajo se ubica en el análisis de los discursos indigenistas del Boletín, aquellos de corte social y político, pero, en particular, de los relatos literarios, buscando comprender la "imagen del indio" que ofrecen, esto es, cómo el indigenismo "representó" a la población indígena y su cultura, y el soporte ideológico que sostiene esa imagen: el socialismo, el marxismo, el surrealismo, la utopía. No se trata de mostrar o criticar la "autenticidad" o "falsedad" de la representación, sino las contradicciones

1 Véase Fabre, El indigenismo, para distinguir entre lo que denomina corriente y movimiento dentro del indigenismo; el movimiento posee una densidad ideológica de la que carece la más laxa opinión favorable hacia los indígenas que se puede identificar desde casi el descubrimiento con un defensor clave como Bartolomé de las Casas. Fabre vincula el “movimiento" indigenista con el siglo XIX y la conformación (difícil y frágil) del Estado-nación, nexo que vuelve a ser visible en la década del veinte con el proceso modernizador que impulsa a los intelectuales a pensar e imaginar una nación que integre a todos los sujetos como ciudadanos.

2 Leibner, “Indigenismo, autoridad intelectual...”, p. 468. 
que anidan en los indigenismos y lo que Jorge Coronado ha definido como los contornos o los límites que definen estos indigenismos: la nación. Para Coronado, ${ }^{3}$ "el descubrimiento del indígena” vendría a ser esencial en las meditaciones de los letrados a la hora de imaginar lo que la modernidad podría (o no) significar en los Andes. Esta meditación sobre el proceso modernizador se desenvolvía la mayor parte de las ocasiones en el marco de una "peruanidad", una consideración sobre la nación peruana como algo a construir (partiendo precisamente de la constatada fragilidad del Estadonación) involucrando en ella a las "masas indígenas" hasta entonces no tenidas en cuenta. Para algunos esa incorporación se logra mediante la instrucción, para otros, mediante mejoras morales, pero en la mayoría de los casos, aun cuando no se exprese así, implica cierta aculturación necesaria para un proyecto que aspira y ve en el futuro lo que no existe en el presente. Las representaciones del indio pocas veces lo hacen de su cultura (la viva), las más de las ocasiones se "incorporan" a una identidad o un proyecto de futuro propuesto desde el centro; se les abre el camino para su incorporación en el proyecto nacional, no tanto para considerar una "identidad comunitaria" de orden regional, diferente a la que se propone desde los espacios centrales. ${ }^{4}$ El horizonte sigue siendo la nación. Eso es particularmente visible en los ensayos de contenido político o social; en los relatos ficticios, sin embargo, como vamos a ver más adelante, es posible encontrar una búsqueda por representar la cultura indígena en sus aspectos vivos y presentes. El aporte de este trabajo se ubica precisamente en el análisis de estos aspectos no considerados en el indigenismo literario (leídos desde la heterogeneidad propuesta por Antonio Cornejo Polar) y en su contraste con las propuestas ensayísticas, todo lo cual abunda en el conocimiento de las contradicciones del indigenismo en los años veinte y en la necesidad de pluralizar el concepto: más que movimiento indigenista, movimientos indigenistas, o indigenismos. Se postula que las narraciones artísticas son más permeables a las

3 Coronado (The Andes Imagined...) enfoca su trabajo no solamente en la representación del indígena, sino que ve el indigenismo como estrechamente vinculado con la modernización y la modernidad, y por ello, como "comentario y reacción” a la aparición e implementación de la modernización en las marginales regiones andinas.

4 Dice Coronado: "While we might immediately think of the preponderant turn in recent critical theory to a concern with identities marginal to dominant constructs of nation (gender, sexuality, and race, among others), indigenista Works of the 1920s and 1930s did not generally seek to articulate a comunal identity at the margins. As Silvia Rosman has commented, while critical paradigms that challenge dominant national identity, such as a postcolonialism and queer theory ton ame but two, seek to designate identities at some distance from the centers of power, they continue to rely on and reiterate the idea of nation in order to do so. The nation still provides the contours of these identities, even as they mark its limits" (The Andes Imagined..., p. 13). 
contradicciones que existen en la heterogénea realidad sociocultural peruana, y que hacen visibles tensiones de otro modo acalladas. Los relatos indigenistas del Boletín Titikaka, elaborados por puneños, buscan mostrar a los indígenas como poseedores de una cultura propia. Éste sería su aporte a los debates y las polémicas del indigenismo.

\section{Gamaliel Churata, el Boletín Titikaka Y EL GRUPO ORKOPATA}

El Boletín Titikaka ${ }^{5}$ fue una publicación cultural (en realidad una hoja doblada que da cuatro páginas) editada entre 1926 y 1930 en Puno, una pequeña ciudad de Perú, de población mayoritariamente indígena (quechua y aymara), situada en los Andes, a 3800 metros sobre el nivel del mar y a las orillas del lago que se considera la cuna de la cultura aymara, el Titikaka. A pesar de su ubicación en un centro rural y de su aislamiento geográfico, el Boletín Titikaka logró establecer una red de canjes por medio de la cual llegó y mantuvo contacto con la mayoría de los países latinoamericanos, quizá por ello en su segundo periodo de aparición el boletín añadió bajo su título: Circulación Continental. Su caso se inscribe en una expansión de iniciativas periodísticas pequeñas, con frecuencia de corta duración, que surgen en Perú entre 1910 y $1930^{6}$ y que inauguran espacios de disputa cultural e ideológica distintos a los localizados en Lima; son tribunas de discusión como expre-

5 La publicación comenzó denominándose Editorial Titikaka Boletín. Al año invirtió el orden y salió como Boletín Editorial Titikaka; en diciembre de 1928 pasó a denominarse Boletín Titikaka. Con el fin de simplificar, en este artículo nos referiremos siempre al Boletín Titikaka, la denominación con la que se le conoce en general (véanse, sobre estos aspectos de la publicación, Cynthia Vich, Indigenismo de vanguardia en el Perú..., 2000; Aymará de Llano, "Vanguardismo a 3800 metros...”, 2007; Agustina Ibáñez, “Boletín Titikaka: Carlos Oquendo de Amat...”, 2017; Begoña Pulido, El Boletín Titikaka y la vanguardia..., 2017). Entre agosto de 1926 y agosto de 1928 se editó mensualmente de forma regular. El número siguiente es de diciembre de ese mismo año y hasta agosto de 1929 volvió a salir regularmente y en un formato mayor. El último número es de 1930 y se dedicó de forma completa a José Carlos Mariátegui, en un sentido homenaje tras su muerte. En total salieron por lo tanto 35 números. En las citas utilizaremos la edición facsimilar llevada a cabo por Dante Callo Cuno. Boletín Titikaka, edición facsimilar, Arequipa, 2004, 2 vols. (abreviación como BT). No fue sino hasta el momento de esta publicación cuando se facilitó su estudio dentro y fuera de Perú. En este artículo (a diferencia del trabajo llevado a cabo en el libro) analizo en particular el indigenismo literario del Boletín, un trabajo que no ha sido hecho de modo profundo. El análisis se lleva a cabo desde la perspectiva abierta por Cornejo Polar sobre la heterogeneidad y cómo los relatos ficticios figuran artísticamente las tensiones abiertas sobre las posibilidades o imposibilidades del diálogo sociocultural.

Véase el trabajo de López Lenci, El laboratorio de la vanguardia..., 1999. 
sión de los sectores medios crecientes; son también una reacción de las provincias con fuerte población indígena contra los dictados de Lima.

Como lo destaca el título, el BT nace como el boletín de una editorial que busca sobre todo editar literatura (poesía en particular) que participe de lo que se dio en llamar "arte nuevo" o arte de vanguardia. Pero así como se rige por una perspectiva nueva, revolucionaria en el arte, cansada de los juegos del modernismo, manifiesta también la necesidad de conciliar la nueva estética con una función social y con una mirada ideológica del arte: éste debe realizar la fusión, dice Gamaliel Churata, su director, con "el sentido y trascendencia políticos que toda obra de pensamiento presupone" (BT, abril de 1928: 87). ${ }^{7}$ Por el contexto en el que surge, la cuna de la cultura aymara, este sentido político tiene una base indigenista, en particular andinista. Es así como a la propuesta del boletín se le ha denominado "vanguardia andina”, ${ }^{8}$ conciliando los opuestos de la revolución estética (que en otros territorios siguió los caminos del arte puro o el arte por el arte) y la revolución política desde el indigenismo (reivindicación de los derechos y las culturas indígenas, del indio como representante y base de la nacionalidad). Revolución en la vanguardia, vanguardia en la revolución. ${ }^{9}$ En el Boletín encontramos ejemplos de literatura perteneciente a la vanguardia andina (en particular poesía de los hermanos Peralta, particularmente del poemario Ande de Alejandro) y también artículos que abordan diferentes aspectos del entonces denominado "problema del indio" desde distintas posiciones ideológicas y políticas. El indigenismo literario y el indigenismo político comparten espacio en los años veinte (en los treinta el político se diluye), como parte de las imbricaciones y difíciles delimitaciones entre los campos político y cultural. El indigenismo es en este periodo, a decir de Antonio Cornejo Polar, "núcleo concentrador de vastas fuerzas ideológicas y estéticas". ${ }^{10}$

En estos años, "la discusión de la cuestión agraria o campesina y del problema nacional se planteará con mayor profundidad y realismo y pasará a convertirse en el eje central del debate político". ${ }^{11}$ De hecho, partidos de

7 El puneño Emilio Armaza dice en una entrevista que aparece en BT, XXV, diciembre de 1928: “creo que el sentido político de nuestra literatura es el semen de sus propias grandezas. Emociones venidas de lo subconsciente desde generaciones atrás son las gotas de nuestro río artístico; y nunca nuestra pasión por las realizaciones políticas revolucionarias fue más pura y más honda”.

8 Véase Cynthia Vich, Indigenismo de vanguardia..., 2000.

9 Emilio Armaza señala también: "Unidas en sístole y diástole, la tendencia vanguardista y la vernácula constituyen, hoy, la médula de la literatura indoamericana” (Armaza, en BT, núm. XXV, diciembre de 1928).

10 Antonio Cornejo Polar, Literatura y sociedad en el Perú: la novela indigenista, 1980, p. V.

11 Cita de Augusta Alfajeme y Mariano Valderrama ("El surgimiento de la cuestión agraria y del llamado problema indígena”, en Degregori, Indigenismo, clases sociales y problema na- 
nueva creación como el APRA o el Partido Socialista, más tarde convertido en el Partido Comunista, y en general los movimientos de lucha social incluyen siempre al indígena y al campesino (pensado en términos de clase y no tanto de cultura) como los más afectados por un sistema injusto que los oprime social y económicamente. En otro ángulo del problema, los ineludibles debates sobre la nacionalidad peruana en la década del veinte introducen una mirada que busca incluir al indio en las perspectivas de futuro de otra forma que no sea mediante su asimilación, disolución o simplemente desaparición en el crisol de la nación. ${ }^{12}$ En el periodo surgen, asimismo, las perspectivas culturales de una naciente antropología que fusionando historia y etnografía "reconocen" la riqueza y el valor civilizatorio de culturas prehispánicas como la inca (son ejemplo obras como El indio nuevo, de Uriel García, o Tempestad en los Andes, de Luis Valcárcel); en sus ensayos se estudia y explica el funcionamiento milenario de las comunidades (los ayllu), o prácticas como el ama suwa, ama llulla, ama quella, buscando vincular pasado y presente indígena. Los indigenismos del periodo analizan el llamado problema del indio desde perspectivas disímiles. Su representación, las distintas configuraciones del indio que podamos encontrar conjuran los problemas de la heterogeneidad sociocultural, la modernidad y la nación. En todos los casos que aparecen en el Boletín, se postula la reivindicación del indio como una tarea urgente y necesaria, pero en ocasiones el problema, y como consecuencia la representación del indio en el discurso, se concibe como una cuestión de instrucción, en otras, como un problema de base económica que solamente se solucionará acabando con el gamonalismo y la servidumbre, o como una cuestión de lucha de clases (que postula la participación del campesinado en las luchas revolucionarias que traerán como consecuencia su liberación). El Boletín Titikaka publica breves ensayos de reivindicación indígena que hacen visibles las distintas tendencias del indigenismo (para unos un problema económico, para otros social o cultural). En los relatos de ficción, sin embargo, la representación del indio incluye una perspectiva cultural, no sólo es evocado como objeto sobre el que se ejerce la instrucción, o como vía para la necesaria modernización de la nación, sino como sujeto poseedor y productor de una fuerte cultura (creencias religiosas, lenguaje quechua, rituales).

David Wise ha llamado la atención sobre la pluralidad de indigenismos en este periodo; señala que el término fue muy manoseado y que la "reivindicación indígena” poseía contenidos fluctuantes según los grupos sociales;

cional, 1978, p. 62) tomada de Wise, “Indigenismo de izquierda y de derecha...”, 1983, p. 160 .

12 Véase Patricia Funes, Salvar la nación... 
en su opinión sería más acertado pluralizar y hablar de indigenismos. Dice David Wise:

\begin{abstract}
Durante los años veinte habría que hablar del "indigenismo" de los mismos sectores terratenientes, del pensamiento ilustrado de derecha, del de la pequeña burguesía radicalizada, sea de Lima o de provincias, y, finalmente, del indigenismo marxista de José Carlos Mariátegui y de los jóvenes comunistas del Cuzco. Habría que hablar, tal vez en primer lugar, del indigenismo “oficial”, patrocinado por el gobierno desarrollista de Augusto B. Leguía, [...] No se solidificaría el indigenismo, durante el oncenio leguista, en una ideología estable ni homogénea. Los intereses de clase, al par de influencias intelectuales de diversa índole conformaron de diferentes maneras las posturas "indigenistas" adoptadas por determinados grupos. ${ }^{13}$
\end{abstract}

El "descubrimiento del indio" por el intelectual de clase media (limeño o de provincia) había comenzado mucho antes de la llamada "Patria nueva" del segundo periodo presidencial de Leguía. Manuel González Prada, en "Nuestros indios", desplazó la mirada sobre la "cuestión indígena" de su enfoque pedagógico predominante (solamente mediante la educación podrá el indígena salir del atraso e incorporarse al proceso modernizador nacional) para asegurar que el problema era de servidumbre y por tanto, económico y social. Más que aceptar con resignación y humildad, la solución debía ser revolucionaria. Esta perspectiva la retomará el indigenismo marxista de José Carlos Mariátegui y también el del APRA (al menos antes de la ruptura). Con la afirmación de que el indio se redimiría merced a su esfuerzo propio, y no por la humanización de sus opresores, se aceptaba la necesidad del radicalismo en los cambios, los cuales debían ser llevados por mano propia, y se criticaba el humanismo paternalista, el filantropismo de blancos y mestizos. Estas opiniones hacían visible, asimismo, la grieta del indigenismo, su exterioridad y la heterogeneidad subyacente, un acto reivindicador que se ejerce desde el exterior del mundo indígena (lo que afecta a la propia representación, una estilización del indio más que una comprensión de su cultura).

En la década de los veinte, los indigenismos se mueven entre posiciones reformistas, educativas, que en buena medida vienen desde la década anterior (una figura importante es el profesor puneño José Antonio Encinas, maestro de buena parte de los integrantes del Grupo Orkopata y una figura influyente en el grupo), y otras socialistas o marxistas, que promueven la vía revolucionaria, el cambio social; éstas fueron vistas como una amenaza por

13 Wise, “Indigenismo de izquierda y de derecha...”, pp. 160-161. 
el gobierno de Leguía y dieron lugar a enfrentamientos, represión y exilio. Otras perspectivas, como las apadrinadas por historiadores y científicos sociales (iniciadores de la etnología en el Perú), revaloraron la civilización inca y reivindicaron la cultura andina; algunos abogaron por un "renacimiento incaico", una mirada utópica, de corte mesiánico, liderada por el cuzqueño Luis E. Valcárcel. Otro cuzqueño, Uriel García, defendió, no la utopía retrospectiva, sino el mestizaje, bajo la idea de un "indio nuevo". Entre las dos posiciones extremas, la pedagógica y la revolucionaria, ambas concebidas como prácticas sociales, estas últimas perspectivas de historiadores y etnólogos apuntan a la reflexión y la interpretación poniendo en relación pasado y presente, buscando integrar una perspectiva histórica al problema indígena actual. ${ }^{14}$ De esta forma se llega a la valoración del universo indígena como una cultura de raíces prehispánicas que se preserva en buena medida. Como decía anteriormente, los distintos indigenismos van a conceder importancia diversa a lo social, lo económico y lo cultural.

En el periodo son de gran influencia los planteamientos de José Carlos Mariátegui sobre la raíz económica del problema indígena (con base en el latifundio y el gamonalismo), el carácter escindido y conflictivo de la sociedad peruana ("la dualidad de la historia y el alma peruanas"), ${ }^{15}$ la contradicción de la base social del indigenismo (entre indígena e indigenista), el carácter no orgánicamente nacional de la literatura peruana (que planteó en los Siete ensayos de interpretación de la realidad peruana), así como la heterogeneidad que marca la propia literatura indigenista, derivada de la movilización de los atributos de una cultura para dar razón de otra distinta. ${ }^{16}$ El Boletín Titikaka mantiene relación con Amauta y con José Carlos Mariátegui, ${ }^{17}$ quien aparece como colaborador en el boletín aun cuando no se publican sus textos sobre el indigenismo. Es comentarista del poemario Ande de Alejandro Peralta, publica un ensayo sobre el realismo proletario de la novela El cemento, de Fedor Cladkov, y en general está presente en diversas alusiones y promoción de Amauta. ${ }^{18}$ El último número del Boletín que ve la luz en 1930 está enteramente dedicado a homenajear a Mariátegui, fallecido

14 Valcárcel y García son autores de ensayos de interpretación del problema indígena: Tempestad en los Andes es de 1927, y El nuevo indio, aunque fue publicado en 1930 como libro, apareció en diversas revistas desde 1928, entre ellas El Boletín Titikaka y Amauta.

15 Mariátegui, Siete ensayos de interpretación..., p. 177.

16 Cornejo Polar, "La novela indigenista: una desgarrada conciencia de la historia”, p. 23.

17 De hecho, Gamaliel Churata es el responsable en Puno de la difusión y las suscripciones de la revista de Mariátegui. La correspondencia permite entrever el intercambio de textos (en particular las colaboraciones de puneños en Amauta).

18 “Preludio del Elogio de 'EL CEMENTO' y del REALISMO PROLETARIO”, Boletín Titikaka, julio de 1929. 
el 16 de abril de ese año. Churata publica en un par de ocasiones en la revista limeña (sus relatos indigenistas "El gamonal” y "Tojjras"); se conserva asimismo una correspondencia (escasa) entre ambos donde se alude a las colaboraciones y a veces a cuestiones personales. David Wise considera a Amauta un "gran foro indigenista", un espacio donde se discuten los aspectos más importantes del indigenismo de la década del veinte. El Boletín no tiene las dimensiones ni los alcances de un foro como el que construyó Mariátegui (aunque coinciden temporalmente), en buena medida porque se edita desde una pequeña y aislada ciudad al tiempo que la revista de Mariátegui se publica en Lima. Sin embargo, participa también en los debates; lo interesante es precisamente ver la perspectiva sobre el problema desde una ciudad y una región alejadas de la capital, con presencia mayoritaria de población indígena y una historia larga de luchas y levantamientos indígenas. ${ }^{19}$ Para los "intelectuales Titikaka" la "cuestión indígena" es una preocupación central; el estudio de la inserción y participación del Boletín en las polémicas contribuye a la comprensión de los indigenismos del periodo y al modo en que los autores puneños (en particular Gamaliel Churata) elaboran un indigenismo literario que busca mostrar al indio con una cultura propia.

Conviene detenerse brevemente en considerar a la figura dirigente y al grupo detrás de esta publicación, cuáles son sus orígenes, cuáles son también sus intenciones, el modo como desean incidir en el medio social y cultural en el que surgen, a quién dirigen una publicación como el Boletín Titikaka.

El director del boletín es Arturo Peralta (1897-1969, conocido como Gamaliel Churata sobre todo a partir de 1924), apoyado por sus hermanos Alejandro, poeta, autor del poemario Ande, en torno al cual va a girar el primer año de la publicación, y Diego, artista plástico, grabador que firma como Kunurana y cuya obra ilustra buena parte de los números (siempre con una perspectiva andinista). Junto al fondo familiar, la crítica ha señalado la presencia de un grupo de escritores, intelectuales (en buena medida autodidactas), profesionistas, que se reunían en la casa de Churata para compartir lecturas, y que publican en el boletín: Mateo Jaika, Emilio Vásquez, Eustakio Aweranka, Inocencio Mamani; además, en ocasiones se unían Julián Palacios, Francisco Chukiwanka, Emilio Romero, Luis de Rodrigo, Emilio Armaza, Segundo Núñez Valdivia. ${ }^{20}$ Quizá habría que resaltar que en el

El libro de José Tamayo Herrera, Historia social e indigenismo en el Altiplano (con prólogo de Emilio Romero, Lima, Ediciones Treintaitrés, 1982), sigue siendo importante a la hora de obtener información, escasa, del grupo. Allí se recogen testimonios de los propios actores, aunque la información es contradictoria a veces. Alude al proceso de mitificación que ha sufrido el grupo entre los puneños y a las dificultades que enfrenta el historiador a la hora de distinguir entre el Ork’opata (sic) mítico y el histórico. Señala asimismo que la ciudad de 
Perú de las dos primeras décadas del siglo Xx no eran las universidades las que concentraban el papel rector de la cultura (de hecho Puno carecía de centro universitario). La intelligentzia se daba cita en otros espacios, tertulias de círculos literarios, conversatorios, asociaciones, periódicos, revistas. ${ }^{21}$ Es en este escenario donde Churata conforma el Grupo Orkopata.

Arturo Peralta había participado anteriormente en la Asociación ProIndígena, una institución privada, al margen del Estado, fundada en 1909, que buscaba algo más que sensibilizar y movilizar a la opinión pública acerca del llamado "problema del indio"; apoyaba legalmente las quejas y reivindicaciones de los indígenas, designaba abogados para defenderlos gratuitamente, enviaba comisionados especiales a cualquier punto del país en el que ocurriese algún conflicto. La intención era convertir a los indígenas en ciudadanos conscientes de sus derechos y con capacidad para demandar lo que por ley les correspondía; por otro, tenían claridad en que la nacionalidad no se podía pensar al margen del indio. Recusaron la tesis del exterminio de los indios considerándola precisamente "un suicidio de la nacionalidad peruana", 22 ya que el indio "está encarnado en la entraña misma del organismo nacional". El cambio que se produce en este periodo de las primeras décadas del siglo veinte es que los indígenas entran a formar parte del debate nacional (por supuesto con ideologías diferentes) pues se parte del Perú como nación irrealizada, una "nacionalidad en formación"

Puno en esos años no apreció el trabajo del grupo y que ignoraba su existencia (no existen por ejemplo alusiones en la prensa). Habría que apuntar que la bibliografía en torno al grupo y en torno a Churata ha crecido en los últimos años. Esta "reivindicación" de una figura olvidada durante décadas obedece en mi opinión a un renacimiento de los indigenismos (desde posiciones teóricas y disciplinarias muy disímiles) en las últimas décadas. El desarrollo y la expansión de los estudios culturales y de las teorías poscoloniales han contribuido sin duda a que "el indígena" sea parte importante de la agenda académica. Algunas de las obras de esta reciente y amplia bibliografía que indagan en Churata y su obra (en particular sobre El pez de oro), así como en el Boletín Titikaka, en menor grado, son: Cynthia Vich, Indigenismo de vanguardia en el Perú: un estudio sobre el Boletín Titkaka (Lima, Fondo Editorial FUCP, 2000); Ulises Juan Zevallos, Indigenismo y nación: los retos de la representación de la subalternidad aymara y quechua en el Boletín Titikaka (Lima, IFEA, 2002); Arturo Vilchis, Arturo Pablo Peralta Miranda. Travesía de un itinerante (México, América Nuestra-Rumi Maki, 2008); Manuel Pantigoso, El ultraorbicismo en el pensamiento de Gamaliel Churata (Lima, Universidad Ricardo Palma, 1999); Mabel Moraña, Churata poscolonial, Lima, Latinoamericana Ediciones/Centro de Estudios Literarios Antonio Cornejo Polar, 2015); Marco Thomas Bosshard, Churata y la vanguardia andina (Lima, Centro de Estudios Literarios Antonio Cornejo Polar/Latinoamericana Editores, 2014); José Luis Ayala (ed.), Innata vocación del escritor Gamaliel Churata (Lima, Pakarina Ediciones, 2017); Begoña Pulido, El Boletín Titikaka y la vanguardia andina (México, CIALC-UNAM, 2017).

21 De hecho, Churata participa a lo largo de su vida en otros grupos culturales como Bohemia Andina y Gesta Bárbara (este último en Bolivia), y en general se le reconoce su capacidad de gestión cultural.

22 Kapsoli, El pensamiento de la Asociación Pro-Indígena, p. 3. 
(dice José Carlos Mariátegui). Desde las provincias peruanas (Cuzco en particular, pero asimismo desde Arequipa, Trujillo o Puno), por medio de revistas o de la creación de tertulias o círculos literarios, crecen los debates sobre el "problema indígena", sobre el carácter de la sociedad peruana (interpretado de forma dualista sierra-costa), sobre la nacionalidad.

El Boletín Titikaka es entonces, entre otras cosas, una publicación indigenista. Pero el indigenismo, entendido como la acción reivindicadora del indio a partir del reconocimiento de su precaria situación socio-cultural, nace de la índole disgregada de la realidad peruana y se ejerce desde fuera del universo al que refiere, señala Antonio Cornejo Polar. ${ }^{23}$ Junto a este señalamiento, el crítico menciona asimismo otra cuestión que me parece muy productiva, y es que en los indigenismos prevalece siempre una contradicción entre la preservación y el cambio del mundo indígena; una doble y contradictoria urgencia: "la de cambiar la realidad y preservar la raíz nativa de la nacionalidad"; 24 "la urgencia de una transformación social se entraba con la necesidad de preservar la raíz autóctona de la nacionalidad". ${ }^{25}$ Ese conflicto impregna el ideario político de partidos como el APRA o el Partido Socialista, pero también existe en los movimientos que proclaman por ejemplo la restauración incaica. Creo que esta contradicción permanece en el Boletín Titikaka como iremos viendo. Otro aspecto a considerar sobre los diferentes indigenismos es la distinta importancia que conceden a los factores sociales y culturales. En general, los movimientos más decididamente políticos ponían énfasis en la categoría socioeconómica del agro y en la necesidad de acabar con el feudalismo y la servidumbre indígenas, y menos en los conflictos de carácter cultural (cómo buscar el diálogo cultural en el Perú dual); resuelven el conflicto en favor del cambio. Por el contrario, los que reivindicaban las culturas y buscaban el reconocimiento y la valoración de las lenguas o de prácticas comunitarias, ponían el acento en la preservación, pero seguían apuntando a una necesaria transformación. El indigenismo que promueve el Boletín Titikaka resuelve la dualidad de "raza, de lengua y de sentimiento", ${ }^{26}$ que señalaba Mariátegui, considerando el sistema indígena como valioso (como una cultura) y buscando ponerlo en relación con el occidentalizado.

6 Continúa Mariátegui (1963, p. 178): “nacida de la invasión y conquista del Perú autóctono por una raza extranjera que no ha conseguido fusionarse con la raza indígena ni eliminarla ni absorberla". 


\section{EL BOLETÍN TITIKAKA COMO FORO INDIGENISTA}

El primer texto indigenista de prosa no ficcional publicado en el BT pertenece a un puneño, Federico More, y lleva el título de “Andinismo”. ${ }^{27}$ Presentado por Churata como un postulado andinista, una especie de manifiesto, define el perfil indigenista del grupo Orkopata donde los Andes y el hombre andino aparecen como el único horizonte político viable. "El Andinismo y el Continentalismo, de suyo inseparables [...] constituyen las únicas propulsiones que le pueden dar a Suramérica oriente político, confianza moral, originalidad artística y plena honestidad económica. La raza más fuerte, la iniciativa más clara, el paisaje más bello, el agua más limpia, la tierra más longánima, la industria más activa, la inteligencia más seria, las costumbres más sobrias, la voluntad más alta, todo lo encuentran los suramericanos en los Andes” (BT, abril de 1927, p. 39). Es de resaltar que andinismo y continentalismo van juntos, conformando lo que se va a denominar Indoamericanismo. Los Andes se convierten en el símbolo de la unidad suramericana, con lo cual coloca al hombre y la geografía en el centro del proyecto andinista del boletín. Es la misma perspectiva del poemario Ande de Alejandro Peralta. Este andinismo e indoamericanismo se vincula en Churata y los Orkopatas con una concepción más que de lo nacional, de una comunidad transfronteriza, Indoamérica, “nuestra gran patria común”. En estos momentos la represión política provoca la clausura de Amauta y la prisión de Mariátegui (junio de 1927), así como el arresto de estudiantes y obreros en la intervención policial de la Editorial Obrera Claridad. Desde la región andina, en el boletín, Churata desmantela el teatro del complot por parte de una "democracia criolla” corrupta. Dada la situación política, el horizonte de expectativas para pensar la nación está demasiado alejado y aparece más próxima la hermandad indoamericana. Otro elemento que abona a la hermandad continental es el antiimperialismo, causa de buena parte de las represiones y que coincide en ese momento entre grupos intelectuales latinoamericanos en ser apreciado como factor de unión continental.

De hecho, el exilio de Magda Portal, Serafín Delmar y Esteban Pavletich, primero a La Habana y más tarde a México, a partir de los sucesos de junio de 1927, refuerza las relaciones del boletín con el antimperialismo de filiación aprista, y mediante este grupo que formará la célula del APRA en México, con el indigenismo mexicano. Magda Portal y Serafín Delmar son colaboradores asiduos desde el comienzo del boletín, envían comentarios sobre el poemario Ande, publican poemas con cierta frecuencia y, ya desde México, hacen llegar a la publicación artículos sobre el arte nuevo o van-

27 Se trata de un fragmento del libro Deberes del Perú, Chile y Bolivia ante la guerra del Pacífico, publicado en La Paz en 1918. More radicaba en ese momento en Buenos Aires. 
guardista, se comentan sus nuevos libros, y por su mediación se publican poemas o artículos de los estridentistas mexicanos (en particular de Germán List Arzubide, pero también de Manuel Maples Arce), o del intelectual cubano radicado en México Martí Casanovas ("Afrocubanismo artístico", marzo de 1928, p. 85; "Plástica mexicana”, agosto de 1928, pp. 105-106; "La nueva pintura de México, testimonio de cultura indoamericana”, enero de 1929), así como de Diego Rivera ("Estética antimperialista”).

La labor del Boletín Titikaka se inscribiría en un movimiento de carácter continental, el de una "joven intelectualidad indoamericana" que lleva adelante una "labor americanista e indigenista" y al mismo tiempo antiimperialista. Así lo expresa una nota titulada "Solidaridad en la rrebolusion" enviada en diciembre de 1927 a los "Compañeros del boletín Titikaka" por la célula del APRA en México, firmada por Esteban Pavletich, Martí Casanovas, C. M. Cox, Serafín Delmar, Magda Portal, Manuel Vásquez Díaz. Dice: "Enviamos a ustedes nuestro más fraternal saludo por la labor americanista e indigenista que vienen realizando en la valiente hoja que dirijen [sic]. El Boletín de la Editorial 'Titikaka' representa el esfuerzo consciente de vuestro grupo por unir a la más joven intelectualidad indoamericana, en cuyos espíritus estén despiertos los nuevos ideales de justicia social i de emancipación económica de nuestros pueblos, hoy más que nunca amenazados por la garra imperialista de los Estados Unidos” (p. 73).

El indigenismo aprista es de base social, no hay un pensamiento sobre las tradiciones, la historia, la cultura, y los indígenas se asimilan más bien con el campesinado. El problema indígena es para ellos de orden económicopolítico y sólo la alianza entre obreros, campesinos y estudiantes puede lograr la lucha revolucionaria que acabe con el latifundio e instaure el socialismo. Entre los dos polos de la permanencia y el cambio, optarían por transformar la realidad y diluir al indio en la nueva estructura nacional. ${ }^{28}$ Aun cuando no hay una afiliación al APRA, el boletín está muy cercano a ellos en este periodo. ${ }^{29}$

28 "El estudio de la revolución mexicana —el paso de avanzada más firme que se ha dado en América - hecha con elementos campesinos indígenas, nos está probando la virtualidad de estas razas fuertes, abnegadas e inteligentes hasta adaptarse a la civilización ciudadana. La Raza indígena de Perú i Bolivia posee idénticas virtudes que sólo hace falta despertar, incorporándola a la sociedad humana i concediéndole el derecho a la vida que hoy se le niega", "Solidaridad en la rrebolusion", diciembre de 1927, p. 74. Firma la Cédula del APRA en México: Esteban Pavletich, Martín Casanovas, C.M. Cox, Serafín Delmar, Magda Portal, Manuel Vásquez Díaz.

29 Tamayo Herrera considera que "el gran escritor puneño hacia 1930 tenía una ideología más bien afín al APRA de la época, y diversos testimonios apuntan que tenía más de anarquista que de comunista" (Historia social e indigenismo en el Altiplano, p. 253). 
Entre noviembre de 1927 y febrero de 1928 encontramos tres textos del indigenista Uriel García que llevan el título de "El neoindianismo", y una reseña de Tempestad en los Andes, de Luis Valcárcel, que firma Gamaliel Churata. 1927 es el año de Tempestad en los Andes, un libro sin duda significativo y que salió en la editorial Minerva con prólogo de José Carlos Mariátegui. A diferencia de los indigenismos que hemos encontrado hasta ahora, los de García y Valcárcel tienen un sentido muy diferente. Por un lado, contienen una reflexión histórica y la perspectiva pone énfasis en aspectos de la cultura como la vida comunitaria. Sin embargo, Uriel García insiste en que los indios de hoy no son los prehispánicos; el nuevo indio es una especie de mestizo psicológico (no exclusivamente racial) que va a dar lugar a una nueva forma de cultura. Garcilaso de la Vega habría sido el primer neoindio. Aun cuando este indio nuevo tiene raíces en el pasado (García rescata la historia del arte prehispánico), debe vivir y anidar en algo diferente, debe ser medio para una expresión cultural distinta y armónica. Todo su discurso se incluye dentro de la filosofía del mestizaje aculturador, vislumbrado en el marco de un proyecto modernizador de raigambre occidental. El boletín publica el artículo en tres partes, pero no hay comentarios por parte de la dirección, y tampoco vuelve a aparecer.

En cambio Valcárcel tiene una presencia mayor, y de hecho Churata abre el boletín de enero de 1928 con una reseña de Tempestad en los Andes, una colección de "ensayos y relatos en tono lírico-mesiánico". ${ }^{30}$ Valcárcel, al contrario de García, exalta al indio, valora el ayllu y condena al mestizo con su famosa sentencia de que "el mestizaje de las culturas no produce sino deformaciones". El suyo es un proyecto de restauración del inkario, proclama y presagia el cambio social, pero postula al mismo tiempo la defensa del Perú profundo; su indigenismo es representativo de la paradoja que mencionaba Cornejo Polar: preconiza una transformación, pero que restaurara el pasado. El credo de Valcárcel es también andinista, "la sierra es la nacionalidad”, dice. Forman parte del credo, una orientación mística, la fe en una comunidad donde prevalece la fraternidad, la igualdad, la justicia, la confianza en la regeneración de alcance nacional que tendrá su foco de irradiación en los Andes. Se trata de un indigenismo lírico-mesiánico que llama a la necesidad de preservar la raíz autóctona de la nacionalidad; la transformación social en su caso implica la restauración del pasado. En su comentario Churata lo denomina "un libro indianista" que "está llamado a injertarse en la conciencia del pueblo".

30 Wise, “Indigenismo del izquierda y de derecha...,, p. 165. 
El indigenismo puneño tiene presencia en el Boletín Titikaka mediante artículos que refieren a la labor de educadores y juristas muy vinculados al Grupo Orkopata. El propio director suele anteceder estos textos con una pequeña presentación, en la que dialoga con las ideas que se van a exponer. Una de estas importantes figuras del indigenismo puneño que aparece en el boletín es Francisco Chuqiwanqa, defensor legal de los indios (entre ellos, del adventista Manuel Camacho), asesor de Rumi Maqui, miembro de la Asociación Pro-Indígena en la primera década. La obra con la que contribuyó al indigenismo es el "Alfabeto Syentifico Queshwa aymara”, alfabeto fonético con el que se podía escribir en quechua, aymara y español. Su idea de crear una ortografía indoamericana que facilitara la alfabetización indígena fue reivindicada e incluso utilizada por el Boletín Titikaka. La encontramos en reseñas y notas editoriales de Gamaliel Churata. La defensa de las lenguas indígenas aparece asimismo en los anuncios del profesor Julián Palacios sobre la enseñanza del quechua y aymara, otro Orkopata, cercano también a Chuqiwanqa.

Otro miembro del Grupo es Emilio Vásquez, quien presenta el "Plan Programa de la Escuela Ambulante Indígena de ILAVE”. En un largo texto que ocupa casi tres de las cuatro páginas del boletín de junio de 1929, presenta el programa de la escuela, cuya finalidad no es la enseñanza de la lectura y la escritura sino un aprendizaje moral y cívico $^{31}$ que propicie el mejoramiento de la agricultura, la ganadería, la educación física, la higiene (en la habitación, la ropa, la alimentación), la crianza de niños y sobre todo, la erradicación del consumo del alcohol y la coca. Aun cuando estas escuelas ambulantes beneficiarían al campesinado de las cordilleras, muy alejados de los centros urbanos, Churata le reprocha ciertos conceptos equivocados sobre la psicología y la organización de los indios, entre ellos el tópico del indio pleitista o del indio borracho. Pero en conjunto, el texto es una crítica fuerte a los hábitos indígenas. Dice Churata:

Es natural que Vásquez conserve aún conceptos equivocados al juzgar la psicología y organización del indio. Por ejemplo: considerar un vicio el espíritu de pleitista impenitente del aborigen, es desconocer muchas verdades ya de antemano refrendadas. El indio pleitea por instinto de vida; y hay que cultivar

"La Escuela Ambulante debe hacer comprender que él, el indio, es un ciudadano que tiene derechos y deberes que reclamar y cumplir para con el medio social que lo rodea, y para con la Patria que cuida de sus intereses. En una palabra, y en la medida de lo posible, ha de procurar hacer del indígena — sobre todo del adulto - un buen ciudadano, capaz de defender lo que le corresponde por derecho natural, y legislativo también, ante las autoridades y ante la razón, para así no seguir siendo un eterno objeto de explotaciones” (BT, junio de 1929). 
ese espíritu, pues que de su desarrollo depende su capacidad para aceptar la idea abstracta de patriotismo. Además, éticamente, con ética económica, el indio pleitea su parcela, su chujjlla, su musiña, el reducto de su libertad, y no terrenos que no cultiva y que menosmente le sean inútiles. Esta rectificación capital va a ser inmediatamente necesaria al programa, tan simpático por su espíritu, del profesor y compañero Vásquez (BT, junio de 1929).

Casi opuesto en su filosofía y su percepción del indígena es el artículo del profesor Julián Palacios, titulado "La pedagogía de Mayku Qqapa y Mama Ojjllu”, los fundadores del imperio inca. Tamayo Herrera ubica a Palacios en la tendencia pedagógica del indigenismo puneño. La enseñanza fundamental que rescata Palacios en su texto es que los indígenas son "elementos activos, disciplinados i subordinados a las máximas leyes: 'ama suwa, ama llulla, ama quella'”. ${ }^{32}$ La forma de organización que destaca el profesor Palacios es la cooperación en todos los actos sociales (el ayni), los principios de solidaridad y reciprocidad, y en la pedagogía destaca, de hecho, lo contrario de lo que mencionaba Vásquez, la crianza de los niños y niñas en las labores, el respeto, y en general en la formación de hábitos. El reconocimiento de los saberes heredados de Mayku QQapa y Mama Ojjllu podría incluso servir, en su opinión, para reorganizar la educación nacional.

Los tres autores mencionados son indigenistas puneños y sus artículos buscan plantear y resolver problemas concretos de la realidad de Puno, que ayuden a la educación de los indios, a la salida del atraso y a la integración en una nacionalidad. En los tres casos la base del planteamiento indigenista es pedagógica y no económica o social. Supone el punto de vista exterior de quien observa y analiza la realidad desde fuera. Aun cuando la compenetración y el reconocimiento de la otra cultura sea mayor en Julián Palacios (quien finalmente rescata el legado de la cultura indígena), el pasado no es tanto objeto de restauración, sino la base para una pedagogía nacional.

\section{EL INDIGENISMO NARRATIVO}

En el segundo periodo del boletín aparece un conjunto de relatos de difícil clasificación genérica; están escritos por integrantes del Grupo Orkopata y buscan la valoración de las culturas quechua y aymara, y con ello del hombre andino (una valoración que tiene mucho de mirada etnológica). Situados entre el cuento y el relato etnológico, a veces la leyenda, son ejemplo de la fractura indigenista. Estos relatos son: “El kamili”, de Gamaliel Churata;

32 “No seas ladrón, no seas mentiroso, no seas flojo”. 
"Sirena encantadora” y "El ajjachiri”, de Mateo Jaika; “Andina”, de Federico More; y "Marcelino Kanawiri”, de Pastor Ordóñez; todos los autores son "intelectuales titikaka". ${ }^{33}$

Apunta Tomás Escadillo que mientras algunos poetas indigenistas del veinte fueron permeables a los vientos de "vanguardia", lo que se percibe muy bien en el Boletín Titikaka, en las búsquedas poéticas del propio Alejandro Peralta (aun cuando Escajadillo se refiere a Amauta), "no encontramos que haya sucedido lo mismo con la prosa indigenista, que tanto en el tiempo de Mariátegui como en épocas posteriores (con la posible y parcial excepción de Gamaliel Churata y, en menor grado, Adalberto Vallaranos), se mantiene en cánones tradicionales, sin ensayar las licencias y búsquedas formales y técnicas de cierta poesía indigenista". ${ }^{34}$ Tampoco es tanta la narrativa indigenista que aparece en las páginas del boletín, si lo comparamos con la poesía, cuya presencia está en cada página desde el primer día. Si lo mismo sucede en Amauta, a decir de Tomás Escajadillo, sería interesante entender por qué. Por su parte, David Wise apunta a un desfase entre las sublevaciones de indígenas en la década de los diez y las tomas de posiciones políticas por parte de intelectuales provincianos (y en general por sectores más amplios de la pequeña burguesía) en la década del veinte, ${ }^{35}$ así como entre la toma de posiciones radicales de los veinte (marxistas en general) y la expresión literaria de tales opciones. Habrá que esperar a los treinta para que inicie la obra indigenista de Ciro Alegría o de José María Arguedas (y a los cuarenta para que aparezcan novelas como El mundo es ancho y ajeno o Yawar fiesta). Dicho de otra forma, no hay correspondencia entre el radicalismo indigenista de los veinte y las expresiones narrativas del mismo periodo, aparentemente mucho más tradicionales.

El Boletín Titikaka es, como he mencionado, una publicación que se ubica en lo que se ha denominado la vanguardia andina. La literatura que publica es aquella que surge en el periodo de posmodernismo y que busca romper con los oropeles ya desgastados del modernismo. La del vanguardismo andino es una poesía en cierta forma antropologizada: el hombre y el paisaje, la naturaleza, son el centro, pero buscando que las imágenes rompan con el sistema metafórico que pone en relación dos elementos que comparten alguna cualidad. La nueva metáfora procura acercar lo más heterogéneo, aquello que sería difícil pensar como compartiendo algo. Esta metáfora se ejerce, sin embargo, dice Agustina Ibáñez, sobre la vida cotidiana y el paisa"Marcelino Kanawiri” (BT, febrero de 1929).

34 Escajadillo, "El relato indigenista en las páginas de Amauta", p. 182.

35 Wise, "Indigenismo de izquierda y de derecha”, p. 159. 
je andino actual. ${ }^{36}$ La metáfora vanguardista propicia el diálogo sociocultural en esa capacidad de imbricar lo heterogéneo en la imagen. Pero así como la poesía es más permeable al acercamiento entre lo heterogéneo, a la prosa de la época parece costarle la búsqueda de alternativas al realismo contra el que en principio parece definirse el vanguardismo. Ese distanciamiento es ciertamente más sutil, menos identificable por el juego con la imagen metafórica que pretende desconcertar al lector. El referente es, como en la poesía del vanguardismo andino, la realidad viva, actual, presente y cotidiana del indio, pero ¿cómo representarlo en el relato?

¿Cuáles serían los elementos que caracterizan a estas narraciones y que rompen con el relato indigenista anterior? (los cuentos andinos de Enrique López Albújar, por ejemplo, o los de Ventura García Calderón, e incluso la novela de Clorinda Matto de Turner). ${ }^{37}$ No son los elementos que caracterizan al relato típicamente vanguardista: fragmentación, dificultad para reconstruir una historia, juegos con el tiempo... Los caminos son otros, uno es el lirismo (se trata de relatos con una fuerte carga lírica) o en general la poetización de las descripciones y el indio (que bien se pueden vincular con la poesía de la vanguardia); otro consiste en una "etnologización” de la historia que se narra. Esta etnologización afecta a la historia en el sentido de que no se trata ahora de narrar la explotación o la servidumbre (que había sido el objeto de la narrativa anterior, que por su carácter de hacer visible las relaciones de dominio fue considerada como "realista") sino de mostrar y compenetrar al lector con la cosmovisión andina, sus creencias muy diferentes y alejadas de la occidental, sus prácticas muy cercanas a lo que a veces denominamos pensamiento mágico. Es por ello que estos relatos podrían ser considerados como de un "protorrealismo mágico", ${ }^{38}$ un cierto antecedente

36 Agustina Ibáñez opina que lo sobresaliente de Ande no radica en el mero uso de la metáfora sino que “...la peculiaridad del libro de Peralta, pero fundamentalmente de esta estética proclamada por el Boletín, es la concentración en la cotidianidad y en la realidad inmediata. La metáfora deviene excepcional y digno de exaltación en la medida que sirve para 'cantar’ y ‘contar' el mundo andino” (“Boletín Titikaka: Carlos Oquendo de Amat...”, pp. 53-54).

37 Tomás Escajadillo considera que el indigenismo narrativo comienza en Perú con los cuentos de Albújar. La obra de Matto de Turner no sería indigenista sino “indianista”. Según Escajadillo, las condiciones que debe cumplir una obra para merecer la calificación de indigenista son: el sentimiento de reivindicación social, la "superación de ciertos lastres del pasado, especialmente la visión romántica del mundo andino", y una "suficiente proximidad en torno al mundo novelado, el indio y el Ande”. Escajadillo, "El indigenismo narrativo peruano”, p. 118. En los relatos del Boletín los elementos que estoy analizando son aquellos que permiten el acercamiento del indio y el Ande a un lector externo al del referente.

Utilizo el prefijo "proto" para aludir a la condición de "primitivo, anterior, incipiente, que antecede” (significados que el diccionario le atribuye a este prefijo de origen griego). Del mismo modo que se ha hablado de un protorromanticismo, por ejemplo, los elementos que estoy señalando podrían ser leídos como de un incipiente realismo mágico. 
de lo que muy poco después autores como Miguel Ángel Asturias o José María Arguedas (ambos permeados de la antropología, por cierto) comenzarían precisamente a explorar. De hecho, la forma del narrador de estos relatos que encontramos en el boletín (en particular de "El kamili" y "El ajjachiri"), que transitan entre el testimonio, el cuento, la leyenda, el ensayo etnográfico, llama la atención porque el narrador (al mismo tiempo personaje) utiliza el sueño, y en general el onirismo, para penetrar en la cosmovisión indígena; por medio de las experiencias oníricas (que fueron un recurso muy de las vanguardias, en particular del surrealismo) narradas con lirismo, este narrador involucra al lector y lo acerca a este otro mundo.

Por lo anterior, habría que considerar el papel que desempeñó el indigenismo (supuestamente próximo al realismo) en las reconfiguraciones del realismo narrativo y la aparición de lo que posteriormente se denominó realismo mágico. Aun cuando no haya fragmentación o rupturas en la linealidad de la historia, es por la influencia de la etnología y el pensamiento mágico como estos pequeños relatos rompen con el realismo (más allá de si cabría o sería conveniente encasillarlos en un vanguardismo). La figura del narrador tiene otra característica interesante que se vincula asimismo con esa etnologización, y es su mirada o perspectiva testimonial (que tiene sus primeros ejemplos en las crónicas del descubrimiento y la conquista). El narrador es por ello puente entre los dos mundos; busca transmitir y hacer comprensible para el lector occidental una experiencia vivida (aunque sea mediante el sueño). Lirismo, onirismo, testimonio, son los elementos con los que este narrador reconfigura el realismo del relato indigenista. Veamos los relatos que aparecen en el Boletín Titikaka.

“Andina”, del puneño Ernesto More (diciembre de 1928), es un breve relato que vuelve sobre un tema que hasta cierto punto es común en la expresión indigenista: la violencia ejercida por los gamonales ("el joven patrón”) sobre las mujeres indígenas. La perspectiva en este caso es la de un narrador externo al relato que "denuncia" una situación reiterada desde la Conquista. Sólo que en este caso la escena se observa desde el ángulo del patrón escondido que mientras duda sobre cómo actuar ve el encuentro amoroso y armonioso de la muchacha con un joven indígena. La fractura y el desconocimiento entre las dos razas la expresa el narrador desde la conciencia del personaje: "Sabía que siendo blanco i patrón le sería imposible conquistarse el amor de una india. Además, ignoraba el alma de esta raza. Para desdeñar estos pensamientos comenzó a leer a Teócrito, libro que llevara como un consejero para estos momentos” (diciembre de 1928).

De entre todos los relatos que encontramos en el boletín, "Andina” responde más al estereotipo indigenista. Una narrativa de corte social que trata sobre los abusos e injusticias de que es objeto el indio, donde más que per- 
sonajes individuales encontramos representantes de un problema, de una situación, de una raza, y cuyo objetivo es concientizar al lector para que contribuya a poner fin a esa situación de sometimiento del indígena. "Andina” resiste, sin embargo, la tentación de terminar de forma violenta (lo que quizás habría respondido más a la realidad) y lo hace con la imagen feliz de la joven pareja de indígenas (a cuya vista "el joven patrón” no pudo actuar violentamente) y un futuro promisorio. Pero no deja de ser el final que Cornejo Polar describe para algunas novelas indigenistas, las cuales terminan con una imagen idealizada de un futuro promisorio que no se sigue como consecuencia de las acciones de abuso y sometimiento que las más de las veces terminan en tragedia. El final prefigura un futuro que no se desprende del presente, pero que finalmente abre el horizonte de expectativas. Al cambiar el final previsible, "Andina” figura un mejor futuro para la raza indígena.

Hay otros dos relatos que se podrían leer bajo la influencia de la etnología, son "El kamili”, de Gamaliel Churata, y "El ajjachiri”, de Mateo Jaika. "El kamili" (BT, diciembre de 1928) es un relato internamente fracturado y que expresa los límites y alcances del indigenismo de los años veinte; por un lado "muestra", representa a la otra cultura, proporciona una imagen o una estampa que quiere ser viva e interna sobre ciertas prácticas y creencias mágicas, pero cuando finaliza el relato inicia la interpretación y valoración de lo leído. Comienza con un sueño que el narrador-autor le relata al kamili tata Ulogio ("sacerdote de la quqa, oficiante de la sauca divina, plasma de la cultura religiosa del Titikaka”) donde aparecen animales sagrados como el cóndor —-kuntur-, el loro, el uturuncu. El kamilli interpreta lo soñado y descubre la causa del mal que aqueja al narrador-personaje en "La wawa de tuqu que se metió en tu casa". El lenguaje del soñador al relatar su viaje onírico es culto y pleno de imágenes poéticas, lo podríamos ubicar dentro del sistema letrado, literario (“...Veo un cielo profundo, tata Ulogio, y a ciertos caballos de piel fina que, hendiendo la dirección de la tarde, lo atraviesan a galope. El espectáculo me sobrecoge; y quedo atónito, sin explicármelo"); el de tata Ulogio está cargado de quechuismos. Cuando el relato ficcional termina, comienza un ensayo antropológico sobre los rituales con los difuntos o las prácticas sanatorias, y en general, sobre la base religiosa de la medicina indígena y de sus prácticas, sustentadas en el animismo. Estas ceremonias, observadas superficialmente, "son el cuerpo de una inocente prestidigitación, pero viéndolas con hondura adquieren mayor trascendencia o más inquietante significado”. Frente al posible descreimiento por parte del lector, señala el narrador: "Bueno es darse un baño de superstición en estos días de bancarrota y orfandad”. Queda evidenciado el punto de vista de este narrador ubicado donde las creencias pueden ser "supersticiones", puente también entre las dos culturas. "La presencia, aún, 
entre nosotros, del pako o del yatiri ${ }^{39}$ es una ardorosa manifestación de vitalidad psíquica que no ha podido extirpar el predominio de otras razas y otras culturas”.

"El kamili”, como otros relatos de carácter etnográfico que aparecen en el boletín, parece buscar otra forma de representar la índole disgregada de la realidad peruana, así como de plantear un diálogo cultural y la incorporación del indio a la nacionalidad peruana. En esa forma pervive la heterogeneidad que es propia de la literatura indigenista, que se produce y dirige su relato a lectores de un universo sociocultural ajeno al representado (lo que es muy visible en "El kamili"). El propio relato resulta heterogéneo en sus materiales: ficción, ensayo, mito. La fractura es signo de las dificultades de entablar el diálogo cultural que al mismo tiempo promueve; el del narrador con el mundo representado, con el cual busca compenetrarse insertándose como personaje que vive la experiencia sagrada, aun siendo ajeno a esa cultura o cosmovisión; el del mundo representado y el lector urbano letrado, a quien el narrador busca compenetrar también con ese otro ajeno e instarle a considerar su cosmovisión como una cultura. La búsqueda formal de Churata (que remite a la de un diálogo cultural en la realidad, al establecimiento de nexos entre sectores de la disgregada realidad) se desplaza entre géneros: el relato ficcional que representa la experiencia viva de la cosmovisión andina, a la que busca extraer de su valoración como supersticiosa, el comentario etnográfico, que funge como explicación de la experiencia. Estos desplazamientos son huella de la dificultad (¿o de la imposibilidad?) de encontrar el lenguaje del diálogo. Pero, sobre todo, busca "convencer" al lector del valor de esas enseñanzas "que de su vieja y madurada civilización [la del indio] podríamos recibir". ${ }^{40}$

Dice Mauro Mamani: "Entre los humanos hay hombres elegidos que, luego de un complejo proceso de aprendizaje, de una gracia divina o de un saber heredado, se convierten en voces intermedias entre los humanos y los dioses; son una especie de sacerdotes que tienen el privilegio de comunicarse con los dioses. Por ello, cuando se tiene que hacer alguna consulta a la naturaleza o a los dioses, son ellos los encargados de transmitir la voluntad de los hombres a aquello. El yatiri cumple varios roles dentro de la cultura; por su conocimiento privilegiado dentro de su comunidad, son considerados sabios consejeros. Esta sabiduría la toman de sus maestros, de los ancianos de la comunidad o de sus padres. También puede adquirir su saber por una intervención divina, como la caída del rayo. [...] El objetivo fundamental del yatiri es buscar el bienestar de la vida económica, social y política de las familias como una unidad/totalidad”. Quechumara..., pp. 65-66.

40 “Tú eres un 'hereje', me decía tata Ulogio... Hereje me decía tata Ulogio porque me vio vivir sin ceremonia, sin amor a los animales; él sacerdote de hombres que adoran al animal casero, que lo tratan con pulcra humanidad, tenía que ver cuán diversa era mi actitud con el animalito de Dios... ¡ Hoy ya no tata Ulogio, por fortuna! Todo es sagrado en la Tierra, y la nube que pasa y el polvo del camino son dueños de una intención vibrante que va a parir en el sensorio" (BT, diciembre de 1928). 
“El ajjachiri”, de Mateo Jaika (seudónimo de Víctor Enriquez Saavedra, BT, junio de 1929), ${ }^{41}$ es un relato, como "El kamili", narrado en primera persona por el hijo de un estanciero, criador de llamas, alpakas y caballos en la pampa aymara; es una pequeña estampa sobre la doma de los potros salvajes y el carácter del domador (Benito Kaira), alguien cuya naturaleza necesitaba "de la vagancia, y por eso gustaba de la vida de aventura”. "Él no podía cimentarse y cumplía su destino, el del ave: volar, ganar distancias, espacios; aparecer como las auroras y perderse como los crepúsculos. Comprendía esta cruel fatalidad de su destino; pero, a pesar de cumplirlo resignado, para ahogarlo, cantaba sus penas, acompañado de su kirki.” El narrador es puente entre las dos culturas. Aun cuando habita la pampa, es joven y desconoce las artes del domador, a diferencia del padre, quien habla en aymara con Benito Kaira y conoce de sus artes, el narrador va descubriendo ese mundo como testigo y participando del encuentro, de las comidas, del canto. Su descubrimiento, del que nos hace partícipes a los lectores también ajenos a ese mundo, se realiza desde el interior del mundo narrado, pero reproduce el mismo gesto del descubrimiento que significa para nosotros como lectores. Al mismo tiempo que descubre y describe, lo hacemos nosotros, para quienes el narrador resulta el mediador. El lenguaje utilizado incluye palabras en aymara, las cuales pertenecen al lenguaje del padre y del domador. El suyo adopta en ocasiones el de la descripción etnográfica, en otras el lenguaje lírico que busca compenetrarse con los sentimientos y las emociones del canto. "El kirki simbólico del tunquipeño, es el instrumento cuyas armonías tienen el privilegio de dar vida a las piedras y adormecer a los seres vivientes. Se hace de una concha de kirkincho y se le pone wayrurus por ojos; cuerdas de alambre de carretilla y de tripas chiwanqu. Benito por cariño y gusto singular adornó además el suyo con una delgada cintita peruana que colgó de la clavijera”. En cuanto al otro ejemplo, sobre los sentimientos:

¡Cuánto sentimiento derrocha esa alma oscura! ¿Acaso en el dolor de ese canto ingenuo, no hay una requisitoria contra Dios, contra el destino? Esa canción, dulce, ingenua, sentimental, sumiónos en un completo abandono: mi padre se dejó invadir de recuerdos y de ansias de sufrir, y yo me perdí en el mundo de idealidad que el cantor abrió ante mí. Todos, mudos, como si hubié-

41 Cynthia Vich considera que las narraciones que aparecen en el boletín son de corte más bien tradicional y no vanguardista, como puede encontrarse en la poesía publicada. En el caso de "El ajjachiri”, lo piensa cercano al relato costumbrista, con una intención más bien documental, pues "la narración se preocupa por ofrecer un cuadro regional informativo sobre los personajes, las costumbres y otros elementos de la cultura local. Así, se describe la tradición del uso de la coca, la fiesta de la virgen y la música regional" (Indigenismo de vanguardia en el Perú, p. 157). 
ramos dejado de respirar, como si asistiéramos a un rito de la raza, escuchábamos al prodigioso cantor, que esa noche nos hizo dormir arrullados por sus bárbaras melodías.

Aunque compenetrado con el mundo que describe, el narrador entra y sale para aproximar e invitar al lector a penetrar en ese otro mundo.

En relación con estos dos relatos, los de Churata y Jaika, su mirada etnológica, en el sentido de que la intención es mostrar un universo indígena vivo, donde se ha preservado la identidad cultural: prácticas de la curación y la doma, parecería querer responder a la pregunta de ¿cómo narrar el mundo indígena? ¿cómo acercarlo al lector desconocedor de ese universo? Lo hace desde un narrador que pertenece a los dos universos, bien porque sea el hijo de un hacendado que comparte lengua y costumbres con el indígena, bien porque visita al yatiri para resolver un problema. Este narrador-personaje conoce, forma parte del mundo representado, pero también posee el lenguaje (literario, lírico) propio del universo exterior al que va dirigido el relato. Para Churata y Jaika el universo indígena parece narrable solamente desde un narrador-personaje a la vez interior y exterior al universo representado (el gesto del testigo que narra la experiencia). Al ser interior, nos proporciona a los lectores una imagen que no puede ser sino "veraz", al ser el testimonio de quien vio y vivió en ese universo. Al poseer los atributos del letrado, puede traducir y transmitir ese universo al lector externo y ajeno.

Tanto "El kamili" como "El ajjachiri" traslucen en la forma de la narración la búsqueda por traducir un mundo al otro y en esa medida proponer un diálogo cultural. Este diálogo se propicia mediante el lirismo, la voz testimonial y la expresión del pensamiento mágico.

Otro aspecto a destacar es que, a diferencia de lo que sucede con la novela indigenista donde, a decir de Antonio Cornejo Polar, el universo indígena sólo parece novelable "en la medida en que es interferido — agredido casi siempre- desde fuera", ya que ese universo "en su coherencia o en sus conflictos interiores $[\ldots]$ resulta ajeno al indigenismo", ${ }^{42}$ en los dos relatos que analizamos se muestra precisamente la coherencia interna de ese universo, lo que parece ser precisamente la intención del relato y lo que permite leerlos desde un indigenismo no tradicional. Para narrar la coherencia, el narrador es un personaje al mismo tiempo interno y externo, sin que ello implique conflicto o tensión. Es por ello que, más que como relatos, perviven como "imagen" de un universo un tanto ajeno a los cambios y a la historia.

Otro de los relatos del boletín refiere a un "hecho real" ("Marcelino Kanawiri” es el título). El autor, Pastor Ordóñez, es un "distinguido jurisconsulto 
y pedagogo", "tratadista muy versado en etnografía peruana" que posee "no pequeño arsenal de materiales para hacernos la revelación de ese mundo desconcertante del aborigen, donde se agitan ideas realmente asombrosas que no es del casi tipificar como simples resabios de la prehistoria, sino como la existencia de inquietudes que escapan al panteísmo, animismo o naturismo porque pertenecen a una región superior de la inteligencia” (palabras de Churata en la presentación del relato, BT, febrero de 1929). Las creencias a las que se refiere Churata como parte de un sentido de lo trascendental, el narrador las califica como "supersticiones y creencias heredadas"; así, los padres de un niño enfermo buscan al yatiri Marcelino Kanawiri que pueda salvar al pequeño de una muerte inminente, ya que “...comprendían que toda enfermedad es el resultado de la acción castigadora de algún ser superior y misterioso, y que nada es mejor para la cura que desagraviarlo con ofrendas y sacrificios o expulsarlo del cuerpo del enfermo por el poder exorcizante de un brujo, de un yatiri" (BT, febrero de 1929). El relato que sigue cuenta la ceremonia de curación y el accidente en el que el padre, creyendo disparar contra un espíritu, termina con la vida del ayudante del yatiri, Andrés Choke. A pesar de la valoración de Churata, el relato de Ordóñez deja entrever la "descreencia" o desconfianza en esas prácticas donde "Fórmulas mágicas, palabrerías simbólicas, actitudes hieráticas, cuidadosamente estudiadas y, sobre todo, presentes muchas ofrendas para satisfacer al Azoguini o atraer mayormente la voluntad de los espíritus de bien, para luchar con el malo, debían ponerse en práctica". Los saberes tradicionales quedan reducidos a "fórmulas, palabrerías y actitudes estudiadas"; no es necesario reiterar la obvia perspectiva exterior que en este caso resalta el aspecto mercantil de la ceremonia. En este caso no hay idealización ni mitificación.

\section{CONCLUSIONES}

Para Cornejo Polar, la novela indigenista (y el indigenismo como totalidad) no debe comprenderse en relación exclusiva con el mundo indígena, como "la revelación o el esclarecimiento de esa realidad" o como "la reivindicación de sus intereses sociales y la revalorización de su cultura": "tiene que comprenderse, más bien, como un ejercicio cultural que se sitúa en la conflictiva intersección de dos sistemas socioculturales, intentando un diálogo que muchas veces es polémico, y expresando, en el nivel que le corresponde, uno de los problemas medulares de la nacionalidad: su desmembrada y conflictiva constitución”. ${ }^{43}$ Leídos desde esta perspectiva, los relatos que acabamos de analizar aparecen menos constreñidos a un indigenismo próximo

${ }^{43}$ Cornejo Polar, Literatura y sociedad en el Perú..., 1980, p. 88. 
del realismo. Todos los ejemplos de indigenismo narrativo que encontramos en el Boletín Titikaka plasman en su forma la problemática de la heterogeneidad social y cultural en el Perú, figuran los vínculos o las fisuras entre dos universos, buscan, de forma más o menos precaria artísticamente, ponerlos en relación, acercar el universo indígena al polo modernizador. Sin embargo, el diálogo cultural queda figurado como un problema, atraído mediante la mirada etnológica y el lirismo, pero no alcanzado.

Los relatos literarios hacen más visibles las distintas perspectivas y contradicciones de los indigenismos, las tensiones en los modos de representar el mundo andino. En las narraciones del Boletín estas tensiones derivan de la pretensión de representar al otro como poseedor de una "cultura" propia, más allá de la denuncia o la reivindicación social. Es en torno a las búsquedas literarias por la representación de la Otredad (un otro diferente que se busca aproximar al mundo que lo observa, sin que ello implique asimilación) donde el indigenismo narrativo se vuelve más complejo y diverso. Es allí asimismo donde se hace visible la participación del Grupo Orkopata, y en particular Gamaliel Churata, en los debates y polémicas abiertos por el indigenismo en la década del veinte. Una participación que se dio en el marco de revistas y hojas culturales como el Boletín Titikaka.

\section{BIBLIOGRAFÍA}

Ayala, José Luis (ed.), Innata vocación del escritor Gamaliel Churata, Lima, Pakarina Ediciones, 2017.

Boletín Titikaka, edición facsimilar (BT), 2 vols., dirigida por Dante Callo Cuno, Arequipa, Universidad Nacional de San Agustín, 2004.

Bosshard, Marco Thomas, Churata y la vanguardia andina, Teresa Ruiz Rosas (trad. del alemán), Helena Usandizaga (pról.), Lima, Centro de Estudios Literarios Antonio Cornejo Polar-Latinoamericana Editores, 2014.

Cornejo Polar, Antonio, Literatura y sociedad en el Perú: la novela indigenista, Lima, Lasontay, 1980.

, "La novela indigenista: una desgarrada conciencia de la historia”, Lexis, vol. IV, núm. 1, julio, 1980, pp. 76-89.

Coronado, Jorge, The Andes Imagined. Indigenismo, Society, and Modernity, Pittsburgh, University of Pittsburgh Press, 2009. DOI: 10.2307/j.ctt5hjt16

Davies, Thomas M., Jr, Indian Integration in Peru. A Half Century of Experience, 1900-1948, Lincoln, University of Nebraska Press, 1974.

De Llano, Aymará, "Vanguardismo a 3800 metros de altura (1926-1930)", CELEHIS-Revista del Centro de Letras Hispanoamericanas, año 16, núm. 18, 2007, pp.139-151. 
Escajadillo, Tomás G., "El relato indigenista en las páginas de Amauta”, Revista de Crítica Literaria Latinoamericana, año 25, núm. 49, 1999, pp. 177-197. DOI: $10.2307 / 4531032$.

Fabre, Henri, El indigenismo, México, Fondo de Cultura Económica, 1998.

Funes, Patricia, Salvar la nación. Intelectuales, cultura y política en los años veinte latinoamericanos, Buenos Aires, Prometeo Libros, 2006.

Ibáñez, Agustina, "Boletín Titikaka: Carlos Okendo de Amat a 3800 metros de altura”, Perífrasis. Revista de Literatura, Teoría y Crítica, vol. 9, núm. 17, 2018, pp. 45-58. DOI: 10.25025/perifrasis20189.17.03.

Kapsoli, Wilfredo, El pensamiento de la Asociación Pro-Indígena, Cusco, Centro de Estudios Rurales Andinos "Bartolomé de las Casas”, 1990.

Leibner, Gerardo, "Indigenismo, autoridad intelectual y jerarquías sociales: dos reportajes a un reportaje en Amauta”, Histórica, vol. XXVII, núm. 2, 2003, pp. 467-483.

López Lenci, Yazmín, El laboratorio de la vanguardia en el Perú. Trayectoria de una génesis a través de las revistas culturales de los años veinte, Lima, Editorial Horizonte, 1999.

Mamani, Mauro, Quechumara. Proyecto estético-ideológico de Gamaliel Churata, Lima, Fondo Editorial Universidad de Ciencias y Humanidades, 2012.

Mariátegui, José Carlos, Siete ensayos de interpretación de la realidad peruana, Lima, Amauta, 1963.

Moraña, Mabel, Churata poscolonial, Lima, Latinoamericana Editores-Centro de Estudios Literarios Antonio Cornejo Polar, 2015.

Pantigoso, Manuel, El ultraorbicismo en el pensamiento de Gamaliel Churata, Lima, Universidad Ricardo Palma, 1999.

Pulido, Begoña, El Boletín Titikaka y la vanguardia andina, México, CIALC-UnAM, 2017.

Tamayo Herrera, José, Historia social e indigenismo en el Altiplano, Lima, Treintaitrés, 1982.

Vich, Cynthia, Indigenismo de vanguardia en el Perú: un estudio del Boletín Titikaka, Lima, Pontificia Universidad Católica del Perú, 2000.

Vilchis Cedillo, Arturo, Arturo Pablo Peralta Miranda. Travesía de un itinerante, México, América Nuestra-Rumi Maki, 2008.

Wise, David, "Indigenismo de izquierda y de derecha: dos planteamientos de los años 1920”, Revista Iberoamericana, vol. XLIX, núm. 122, enero-marzo 1983, pp. 159-169. DOI: 10.5195/REVIBEROAMER.1983.3772.

Zevallos Aguilar, Ulises Juan, Indigenismo y nación. Los retos a la representación de la subalternidad aymara y quechua en el Boletín Titikaka (1926-1930), Lima, IFEA, 2002. DOI: 10.4000/books.ifea.449 